\title{
Measurement of the energy and power radiated by a pulsed blackbody $x$-ray source
}

\author{
H. C. Ives, ${ }^{1}$ W. A. Stygar, ${ }^{2}$ D. L. Fehl,${ }^{2}$ L. E. Ramirez,${ }^{3}$ S. C. Dropinski, ${ }^{2}$ D. L. Wall, ${ }^{4}$ J. S. Anctil,${ }^{4}$ J. S. McGurn, ${ }^{2}$ \\ J. H. Pyle, ${ }^{3}$ D. L. Hanson, ${ }^{2}$ B. N. Allison, ${ }^{2}$ M. J. Berninger, ${ }^{5}$ E. A. Bryce, ${ }^{2}$ G. A. Chandler, ${ }^{2}$ M. E. Cuneo, ${ }^{2}$ A. J. Fox, ${ }^{3}$ \\ T. L. Gilliland, ${ }^{3}$ C. L. Haslett, ${ }^{3}$ R. J. Leeper, ${ }^{2}$ D. F. Lewis, ${ }^{6}$ M. A. Lucero, ${ }^{2}$ M. G. Mazarakis, ${ }^{2}$ D. H. McDaniel, ${ }^{2}$ \\ J. L. McKenney, ${ }^{2}$ J. A. Mills, ${ }^{2}$ L. P. Mix, ${ }^{2}$ J. L. Porter, ${ }^{2}$ M. B. Ritchey, ${ }^{2}$ L. E. Ruggles, ${ }^{2}$ J. F. Seamen, ${ }^{2}$ W. W. Simpson, ${ }^{2}$ \\ R. B. Spielman, ${ }^{2}$ J. A. Torres, ${ }^{2}$ M. F. Vargas, ${ }^{2}$ T. C. Wagoner,${ }^{3}$ L. K. Warne, ${ }^{2}$ and M. W. York ${ }^{2}$ \\ ${ }^{1} E G \& G$, Albuquerque, New Mexico 87107, USA \\ ${ }^{2}$ Sandia National Laboratories, Albuquerque, New Mexico 87185, USA \\ ${ }^{3}$ Ktech Corporation, Albuquerque, New Mexico 87123, USA \\ ${ }^{4}$ Resonetics Incorporated, Nashua, New Hampshire 03063, USA \\ ${ }^{5}$ Bechtel Nevada, Los Alamos, New Mexico 87544, USA \\ ${ }^{6}$ International Specialty Products, Wayne, New Jersey 07470, USA
}

(Received 10 May 2006; published 8 November 2006)

\begin{abstract}
We have developed a diagnostic system that measures the spectrally integrated (i.e. the total) energy and power radiated by a pulsed blackbody x-ray source. The total-energy-and-power (TEP) diagnostic system is optimized for blackbody temperatures between 50 and $350 \mathrm{eV}$. The system can view apertured sources that radiate energies and powers as high as $2 \mathrm{MJ}$ and $200 \mathrm{TW}$, respectively, and has been successfully tested at $0.84 \mathrm{MJ}$ and $73 \mathrm{TW}$ on the $Z$ pulsed-power accelerator. The TEP system consists of two pinhole arrays, two silicon-diode detectors, and two thin-film nickel bolometers. Each of the two pinhole arrays is paired with a single silicon diode. Each array consists of a $38 \times 38$ square array of $10-\mu \mathrm{m}$-diameter pinholes in a 50- $\mu \mathrm{m}$-thick tantalum plate. The arrays achromatically attenuate the $\mathrm{x}$-ray flux by a factor of $\sim 1800$. The use of such arrays for the attenuation of soft $\mathrm{x}$ rays was first proposed by Turner and co-workers [Rev. Sci. Instrum. 70, 656 (1999)]. The attenuated flux from each array illuminates its associated diode; the diode's output current is recorded by a data-acquisition system with 0.6-ns time resolution. The arrays and diodes are located 19 and $24 \mathrm{~m}$ from the source, respectively. Because the diodes are designed to have an approximately flat spectral sensitivity, the output current from each diode is proportional to the x-ray power. The nickel bolometers are fielded at a slightly different angle from the array-diode combinations, and view (without pinhole attenuation) the same x-ray source. The bolometers measure the total $\mathrm{x}$-ray energy radiated by the source and — on every shot—provide an in situ calibration of the array-diode combinations. Two array-diode pairs and two bolometers are fielded to reduce random uncertainties. An analytic model (which accounts for pinhole-diffraction effects) of the sensitivity of an array-diode combination is presented.
\end{abstract}

DOI: 10.1103/PhysRevSTAB.9.110401

PACS numbers: 52.70.La, 52.59.Qy, 52.50.Jm, 52.57.-z

\section{INTRODUCTION}

$Z$ pinches, laser-generated plasmas, and particle-beamheated targets serve as intense pulsed x-ray sources for inertial-confinement-fusion, radiation-physics, radiationhydrodynamics, astrophysics, and other plasma-physics experiments [1-7]. The spectrum of $\mathrm{x}$ rays emitted by these sources can often be approximated as that of a blackbody.

Two of the most critical measurements that can be made on such experiments are those of the total x-ray energy and peak x-ray power radiated by the source. Because of the nature of such experiments, the source is usually enclosed, and hence is apertured in some manner. Consequently, only part of such a source is available for diagnostic viewing. For many experiments presently being conducted, it is desired to measure energies and powers (radiated by the apertured part of the source) as high as $2 \mathrm{MJ}$ and $200 \mathrm{TW}$, respectively.

As described in Refs. [2-18], intense x-ray sources are often diagnosed using a filtered array of photoemissive
$\mathrm{X}$-ray detectors (XRDs). Since both the filter attenuations and XRD-photocathode sensitivities are functions of the $\mathrm{X}$-ray energy, it is necessary to perform a computational unfold to obtain from the XRD output signals the $\mathrm{x}$-ray spectrum, and from this, the radiated energy and power $[8,12-14]$. If one does not require the spectrum and only wishes to obtain the energy and power, an unfold is not required, as observed by Fehl and colleagues [18]. The energy and power is obtained in Ref. [18] by a computational spectral-equalization process. Spectral equalization can be achieved experimentally as well, with the use of a complex filter and a single XRD, as demonstrated by Kornblum and Slivinsky [19]. Radiated energies and powers can also be measured with a transmission-grating spectrometer, as described in Refs. [11,15,20-23], or a diffractive-slit spectrometer, as described by Baker and colleagues in Ref. [24].

An alternate diagnostic approach - one that does not require filters, XRDs, or a spectrometer-is described by Turner and colleagues [25]. The system described in 
Ref. [25] consists of an array of pinholes and a single unfiltered diamond photoconductive detector. The pinholes are used to attenuate the x-ray flux in an achromatic manner. The attenuated flux illuminates the detector, which has a sensitivity less spectrally dependent than that of an XRD [8,12-19,26-30]. The system described in [25] provides direct measurements of the energy and power radiated by an x-ray source. The measurements are performed without an unfold procedure $[8,12-14,23,24]$ or spectralequalization process $[18,19]$. However, since the measurements are spectrally integrated, they provide no information about the spectrum, which would have to be obtained from other instruments.

Of course, pinholes and photoconductors have some spectral dependence. Hence, the energy and power measurements made with the system described in Ref. [25] are meaningful only when the upper and lower limits of the spectrum are consistent with the designs of the pinholes and photoconductor, and when the response of the diagnostic system is not a sensitive function of the shape of the spectrum.

In this article, we describe an $\mathrm{x}$-ray-diagnostic system that was motivated by and extends the work of Ref. [25]. The system outlined herein uses pinhole arrays similar to that developed by Turner and colleagues [25]. However, instead of diamond photoconductors, we use HS-1 silicon diodes [31] that are apertured, as first recommended by Porter [20]. Such diodes have a flatter spectral response, and hence are less sensitive to the shape of the spectrum, than XRDs [2-19], photoconductors [26-30], and unapertured diodes [32]. In addition, as observed by Idzorek and Bartlett [32], since silicon diodes are volume detectors, their sensitivities do not change significantly over time, as do surface detectors such as XRDs [12]. For these reasons, apertured silicon diodes are used in various diagnostic applications [11,15,20-24,33-36].

The diagnostic system described in this article uses two apertured diodes and two pinhole arrays. Each of the two pinhole arrays is paired with a single diode. The system also includes two thin-film nickel bolometers [37,38] that provide - on every shot - an in situ calibration of the two array-diode combinations. Like the silicon diodes, the bolometers are volume detectors.

Since the arrangement of detectors described in this article measures the spectrally integrated (i.e., the total) energy and power radiated by an x-ray source, we refer to such an arrangement as a total-energy-and-power (TEP) diagnostic system. We expect that TEP systems could be applied to a wide variety of high-energy-density physics experiments; the specific TEP described in this article is a prototype designed to diagnose $z$ pinches driven by the $Z$ pulsed-power accelerator [39-47].

The prototype is described in Sec. II. In Secs. III A, III B, and IIIC, we develop an analytic model (which accounts for pinhole-diffraction effects) of the sensitivity of an array-diode combination. The model makes the simplifying assumption that the x-ray spectrum can be approximated as that of a blackbody, and estimates the sensitivity as a function of the blackbody temperature.

The bolometers that we use were originally developed by Hanson [37] and have been developed further by Spielman and colleagues [38]. Fehl and co-workers have shown that the bolometers provide results that are consistent with those of an absolutely calibrated calorimeter [48]. In Sec. III D, we briefly review the model presented in $[37,38]$ of the relative spectral sensitivity of a bolometer. Analytic estimates of the maximum energy and power that can be diagnosed by a TEP system are developed in Sec. III E.

In Sec. IV, we present results of TEP measurements performed on the $Z$ pulsed-power accelerator [39-47], and compare these to measurements performed with the XRD array described in Refs. [12,13,15,18]. We discuss recommendations for future work in Sec. V.

\section{DESIGN OF A TEP DIAGNOSTIC SYSTEM}

In this section we describe the design of a prototype TEP diagnostic system. The prototype includes two array-diode combinations and two thin-film nickel bolometers.

The configuration of a single array-diode combination is shown in Fig. 1. Figure 2 presents a detailed cross-sectional view of the apertured-diode-detector assembly. Figure 3 is a detailed view of the diode itself [31,32].

For the measurements described herein, the x-ray source of Fig. 1 is a $z$ pinch that is apertured so that $50 \%$ of the total pinch height is visible to the diagnostic system. The two array-diode combinations are nominally identical, are separated by an angle of $0.1^{\circ}$, and view nominally the same axial section of the pinch. The arrays and diodes are located 19 and $24 \mathrm{~m}$ from the $z$ pinch, respectively. A single vacuum line-of-sight pipe contains the two arraydiode combinations. The pipe has space for a third; this space is used instead for alignments performed with a telescope and GAFCHROMIC HD-810 radiochromic film $[48,49]$. The use of such film for the alignment of $\mathrm{x}$-ray diagnostics was first proposed by Fehl and colleagues [48].

Each of the two pinhole plates is similar to that described by Turner and co-workers [25] -i.e., each uses 10 - $\mu \mathrm{m}$-diameter pinholes in a $50-\mu \mathrm{m}$-thick sheet of tantalum. However, instead of using a square $16 \times 16$ array of pinholes in each plate [25], we use a square $38 \times 38$ array, with a center-to-center spacing between pinholes of $361 \mu \mathrm{m}$. Hence, each pinhole plate creates 1444 images. Each image is demagnified by a nominal factor of $19 /(24-19)=3.8$ due to the pinhole-imaging geometry.

To protect the pinhole plates from debris generated by the $z$ pinch, we position a pinhole mask directly in front of, and in contact with, each of the two plates. Each mask has a $38 \times 38$ square array of $127-\mu$ m-diameter holes, each of 


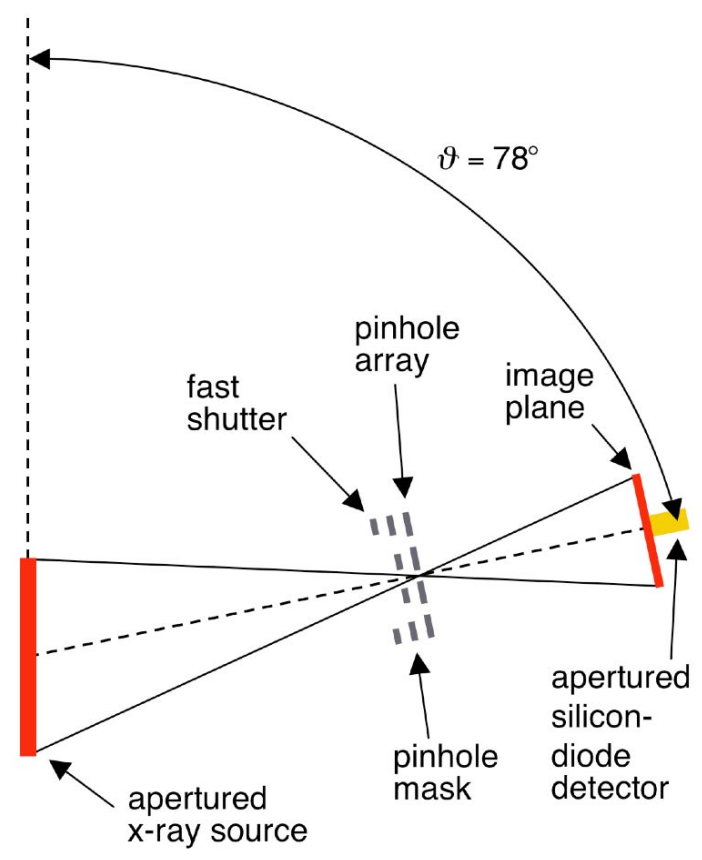

FIG. 1. (Color) Configuration of an array-diode combination. The fast shutter and pinhole mask protect the pinhole array from debris generated by the pinch. Both the mask and array have 1444 holes arranged in a square $38 \times 38$ array. The pinholes generate 1444 images at the image plane. Only three pinholes and one image are shown here. The center-to-center spacing of the pinholes is $361 \mu \mathrm{m}$. The pinhole array and diode are located 19 and $24 \mathrm{~m}$ from the x-ray source, respectively. (This drawing is not to scale.)

which is concentric with a pinhole in a pinhole plate. Each mask covers $90 \%$ of the area of its associated pinhole plate. The fast shutter shown in Fig. 1, which closes within $1 \mathrm{~ms}$ after the x-ray pulse, protects the array-mask combination.

The pinholes were laser machined in the tantalum plate $[25,50]$. A scanning electron micrograph of a typical pinhole is presented in Fig. 4. The nominal diameter of each pinhole is $10 \mu \mathrm{m}$. The actual diameter of each of the 1444 pinholes, in each of the two pinhole plates, was measured with an optical microscope. The diameter of each pinhole was determined from a least-squares analysis of the pinhole's perimeter. Results of the diameter measurements are summarized in Table I. We note that, even though the standard deviations of the diameters are on the order of $10 \%$, the ranges in diameters are large. Although optical measurements do not give the effective diameters of pinholes for $x$ rays with energies of interest, we expect the optical results to be a reasonable approximation to the diameters that would be measured with $\mathrm{x}$ rays.

As suggested by Fig. 1, the 1444 images produced by the pinhole array overlap at the image plane, where the centerto-center spacing between images is $361(24 / 19) \mu \mathrm{m}=$ $456 \mu \mathrm{m}$. Each pinhole plate attenuates the x-ray flux by a factor of $\sim 1800$, which is sufficient to allow the flux at the image plane to be measured with a silicon diode. A

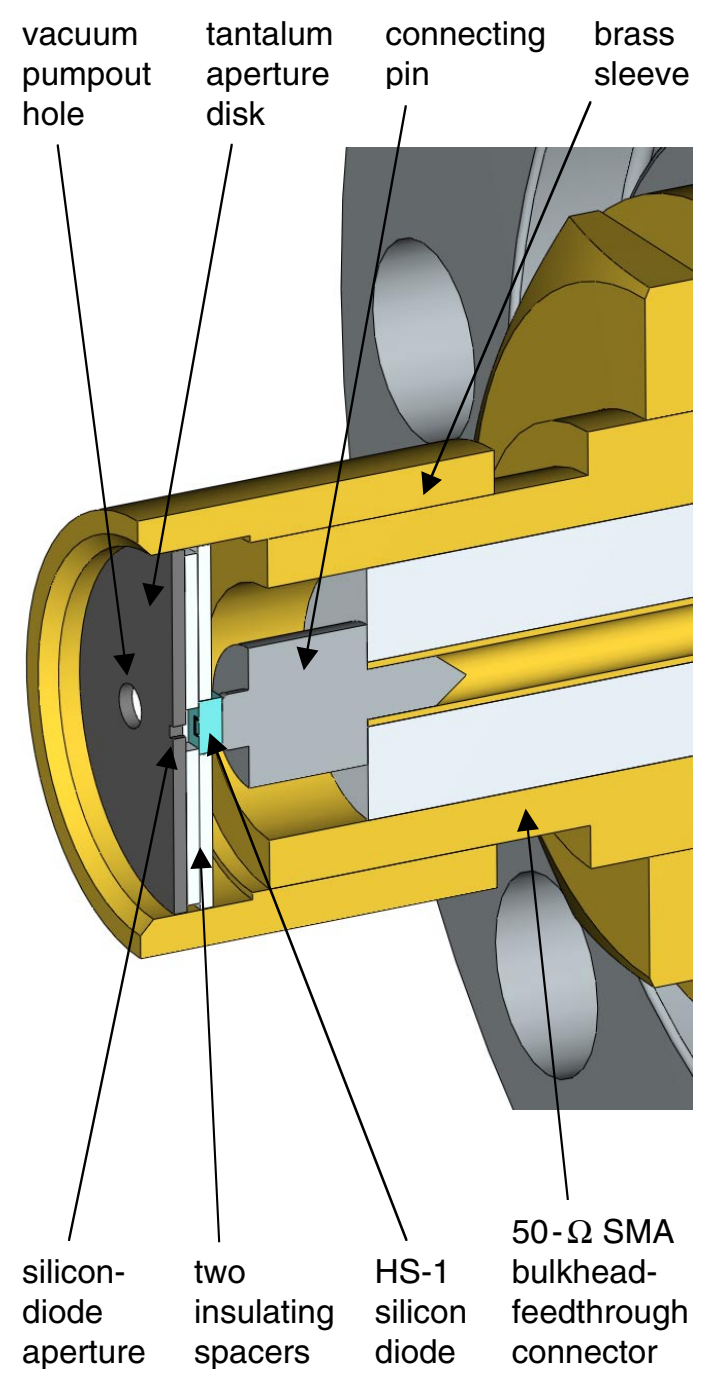

FIG. 2. (Color) Detail of the apertured silicon-diode detector shown in Fig. 1. This drawing is to scale.

detailed discussion of the pinhole attenuation ratio is presented in Sec. III A.

The aperture plate indicated in Fig. 2 is fabricated from tantalum. The plate is located $250 \mu \mathrm{m}$ in front of the diode. The nominal dimensions of the aperture are $200 \mu \mathrm{m} \times$ $200 \mu \mathrm{m}$; the nominal aperture area is $4 \times 10^{-8} \mathrm{~m}^{2}$. The aperture allows $\mathrm{x}$ rays to illuminate only the silicon region inside the diode's cathode-electrode ring, shown in Fig. 3. Hence the aperture flattens the spectral sensitivity of the diode, since without this aperture $\mathrm{x}$ rays would be detected by the region of the diode outside the ring [20]. \{The silicon region inside the ring is coated with 8-11 nm of silicon dioxide $\left(\mathrm{SiO}_{2}\right)$; the region outside is coated with $800 \mathrm{~nm}[32,51]$.$\} We note that the HS-1 diode described in$ Ref. [32] is not apertured. In this case, $\mathrm{x}$ rays illuminate the diode both inside and outside the ring.

As indicated by Fig. 2, each diode is connected to an SMA coaxial connector. The connector has a transmissionline impedance of $50 \Omega$, and is in turn connected to a $50-\Omega$ 


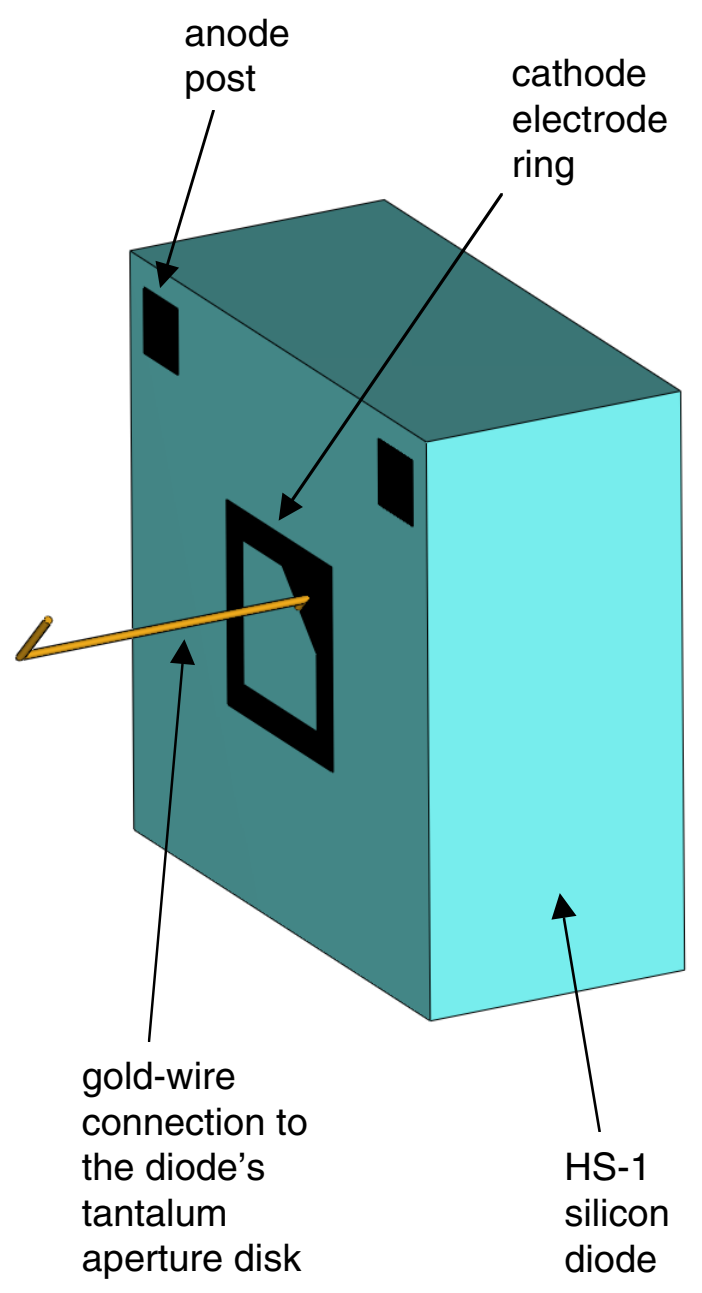

FIG. 3. (Color) Detail of the silicon diode shown in Fig. 2. (In the above view, the diode is shown in its entirety, and not in a cross section.) The back of the diode is covered by the anode electrode, which is in contact with the two anode posts. The dimensions of the diode are $0.96 \mathrm{~mm} \times 0.96 \mathrm{~mm} \times$ $0.45 \mathrm{~mm}$. This drawing is to scale.

data-acquisition system. This system includes coaxial cables, a circuit that permits the application of a 50-V DC bias voltage across the diode, and a transient-waveform digitizer. The digitizer samples the diode output signal every $0.1 \mathrm{~ns}$, and has a $10 \%-90 \%$ rise time of $0.35 \mathrm{~ns}$. The time response of the data-acquisition system as a whole (not including the diode) is dominated by that of the digitizer, and is $0.6 \mathrm{~ns}$ [12]. (The system is essentially identical to that used by Chandler and co-workers for XRD detectors [12].) The diode itself has a 10\%-90\% rise time of $0.1 \mathrm{~ns}$, and a $0.5 \mathrm{~ns}$ fall time [32].

The two thin-film nickel bolometers [37,38] fielded as part of the TEP diagnostic system are nominally identical, are located in a separate vacuum line-of-sight pipe $0.4^{\circ}$ from the silicon diodes, and view (without pinhole attenuation) nominally the same $\mathrm{x}$-ray source. The bolometers are located $19 \mathrm{~m}$ from the source. Each bolometer consists

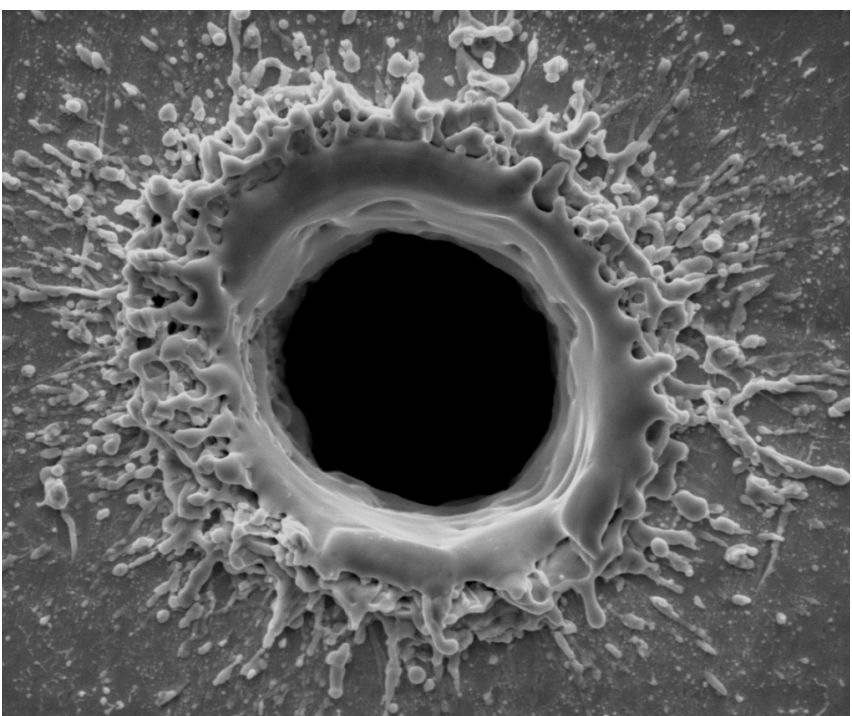

FIG. 4. Scanning electron micrograph of a single lasermachined $10-\mu \mathrm{m}$-diameter pinhole in one of the tantalum pinhole plates. Each of the two pinhole plates has 1444 such holes.

TABLE I. Parameters of the two laser-machined pinhole arrays.

\begin{tabular}{lcc}
\hline \hline \multicolumn{1}{c}{ Parameter } & Pinhole array 1 & Pinhole array 2 \\
\hline Number of pinholes & $1444(38 \times 38)$ & $1444(38 \times 38)$ \\
Average pinhole diameter & $10.07 \mu \mathrm{m}$ & $9.12 \mu \mathrm{m}$ \\
Standard deviation & $0.74 \mu \mathrm{m}$ & $0.88 \mu \mathrm{m}$ \\
Minimum pinhole diameter & $5.47 \mu \mathrm{m}$ & $4.50 \mu \mathrm{m}$ \\
Maximum pinhole diameter & $13.54 \mu \mathrm{m}$ & $24.45 \mu \mathrm{m}$ \\
\hline \hline
\end{tabular}

of a $2 \mathrm{~mm} \times 12.7 \mathrm{~mm}$ rectangular nickel film that is $1 \mu \mathrm{m}$ thick. An aperture limits the exposed length of the film to $10 \mathrm{~mm}$. The deposition of x-ray energy in the film increases the temperature of the film and consequently, the film's resistance. The change in the resistance is measured to infer the deposited energy. The bolometer design is described in detail in Refs. [37,38].

Two array-diode configurations are fielded simultaneously to permit measurements of random variations in the x-ray-power pulse shape obtained with the diodes. Two bolometers are also fielded simultaneously to permit measurements of variations in the values of the total radiated $\mathrm{x}$-ray energy. Average values of the diode and bolometer signals are used to reduce random uncertainties by a factor of $2^{1 / 2}$.

\section{ANALYTIC MODEL OF THE TEP}

\section{A. Spectral dependence of the pinhole-array attenuation ratio}

We define the pinhole-array attenuation ratio $p$ to be the ratio of the x-ray flux at the image plane (i.e., at the location of the silicon-diode detector) to the flux that would 
be present without the pinhole array and mask (i.e., the array-mask combination) illustrated in Fig. 1.

\section{Attenuation ratio excluding diffraction}

We first estimate the attenuation ratio in the absence of pinhole diffraction.

Since the pinhole array consists of a $38 \times 38$ square array of holes, and the center-to-center distance between the holes is $361 \mu \mathrm{m}$, the size of the pinhole array is $13.357 \mathrm{~mm} \times 13.357 \mathrm{~mm}$. When projected onto the image plane (from the center of the source), the array size increases to $16.872 \mathrm{~mm} \times 16.872 \mathrm{~mm}$ (since the array is located $19 \mathrm{~m}$ from the source, and the image plane, $24 \mathrm{~m}$.) There are 1444 images produced at the image plane. The silicon-diode samples the small part of each image that overlaps the diode, as illustrated in Fig. 1.

We assume that (i) the area of each image at the image plane is much larger than the area of the diode's aperture; (ii) spatial variations in the image occur over distances greater than $361(24 / 19) \mu \mathrm{m}=456 \mu \mathrm{m}$; and (iii) each image can fit within a $16.872 \mathrm{~mm} \times 16.872 \mathrm{~mm}$ square. Under these conditions, it is straightforward to show that the fraction $f_{\text {trans }}$ of the x-ray flux at the array-mask combination that is transmitted by the combination, and is subsequently detected by the silicon diode, is approximately given by the following expression:

$$
\begin{aligned}
f_{\text {trans }}(\varepsilon)= & \frac{\pi a^{2}}{d^{2}}+\frac{\pi\left(b^{2}-a^{2}\right)}{d^{2}} \exp \left[-\mu_{\mathrm{Ta}}(\varepsilon) x_{\text {pin }}\right] \\
& +\frac{d^{2}-\pi b^{2}}{d^{2}} \exp \left[-\mu_{\mathrm{Ta}}(\varepsilon)\left(x_{\text {pin }}+x_{\text {mask }}\right)\right] .
\end{aligned}
$$

In the above equation $\varepsilon$ is the x-ray-photon energy, $a$ is the radius of a single pinhole, $d$ is the center-to-center distance between pinholes in the pinhole plate, $b$ is the radius of a single hole in the pinhole mask, $\mu_{\mathrm{Ta}}(\varepsilon)$ is the $\mathrm{x}$-rayattenuation coefficient of tantalum (in units of inverse length), $x_{\text {pin }}$ is the thickness of the tantalum pinhole plate, and $x_{\text {mask }}$ is the thickness of the tantalum pinhole mask. (Equations are in SI units throughout.) Equation (1) neglects (i) x-ray penetration through the corners of the pinholes; (ii) x-ray scattering from the pinhole walls; and (iii) fluorescence of the tantalum.

The first term on the right-hand side of Eq. (1) is the fraction of the incident flux transmitted through the pinholes themselves. The second term is the fraction transmitted through the tantalum material of the pinhole plate (outside the pinholes) that is exposed by the $127-\mu \mathrm{m}$-diameter holes in the pinhole mask. The third term is the fraction transmitted through the tantalum material of both the pinhole plate and mask, outside the holes in the mask. Assuming

$$
\begin{gathered}
a=5 \mu \mathrm{m}, \\
d=361 \mu \mathrm{m},
\end{gathered}
$$

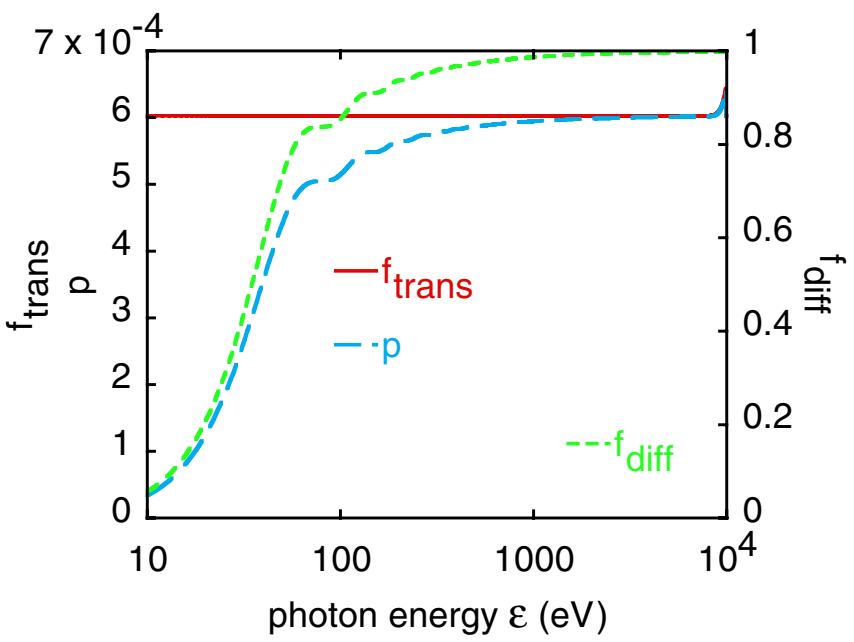

FIG. 5. (Color) The attenuation ratio $p(\varepsilon)=f_{\text {trans }}(\varepsilon) f_{\text {diff }}(\varepsilon)$ of an array-mask combination. Also plotted are $f_{\text {trans }}(\varepsilon)$, the attenuation ratio in the absence of diffraction, and $f_{\text {diff }}(\varepsilon)$, the correction to the attenuation ratio due to diffraction. The quantities are plotted as a function of the x-ray energy $\varepsilon$. As shown in the plot, diffraction considerably increases the attenuation for energies below $100 \mathrm{eV}$.

$$
\begin{gathered}
b=63.5 \mu \mathrm{m}, \\
x_{\text {pin }}=50 \mu \mathrm{m}, \\
x_{\text {mask }}=254 \mu \mathrm{m},
\end{gathered}
$$

and that the energy-dependent attenuation coefficient $\mu_{\mathrm{Ta}}(\varepsilon)$ is as given by Refs. [52,53], we obtain the transmission ratio $f_{\text {trans }}(\varepsilon)$ plotted in Fig. 5. As indicated by the figure, $f_{\text {trans }}(\varepsilon)$ is dominated by the first term on the righthand side of Eq. (1); i.e., most of the $\mathrm{x}$ rays transmitted by an array-mask combination defined by Eqs. (2)-(6) are transmitted through the pinholes.

\section{Attenuation ratio including diffraction}

Because of x-ray diffraction by the pinholes, the actual attenuation ratio differs from that given by Eq. (1). We estimate the effects of diffraction using the following arguments.

As discussed in the previous section, each silicon diode samples the small part of each image that overlaps the diode's aperture, as suggested by Fig. 1. In the absence of diffraction, each of the 1444 images at the image plane would have a finite spatial extent. When in addition the source, pinhole array, and diode are perfectly aligned, and each image can fit within a $16.872 \mathrm{~mm} \times 16.872 \mathrm{~mm}$ square, the diode would sample radiation from throughout the entire image. (For example, when each image is in the shape of an $8.436 \mathrm{~mm} \times 8.436 \mathrm{~mm}$ square, the diode would sample a small part of each of $\sim 361$ images.) Under such conditions, the samples would be uniformly collected from throughout the entire image, and the pinhole attenuation ratio would be approximately given by 
Eq. (1). [Since the aperture of each silicon diode has dimensions on the order of $200 \mu \mathrm{m} \times 200 \mu \mathrm{m}$, and the center-to-center spacing of the images at the image plane is $456 \mu \mathrm{m}$, the diode would sample radiation from approximately $(200 / 456)^{2}=19 \%$ of the image. The samples would be collected uniformly from throughout the entire image.]

In the presence of diffraction, however, each image has, in principle, infinite extent. Since the pinhole array does not extend infinitely over the plane of the array, the diode cannot, in the presence of diffraction, sample x rays from throughout the entire image. Consequently, diffraction causes the x-ray flux at the silicon-diode location to be less than that given by Eq. (1).

To estimate the effect of diffraction on the attenuation ratio, we first consider the diffraction by a single pinhole of monochromatic $\mathrm{x}$ rays emitted by a point $\mathrm{x}$-ray source. Assuming scalar Kirkhoff diffraction theory, and that the diffraction angles of most interest are much less than a radian, the fraction $L$ of the total $x$-ray power at the image plane that falls within a distance $r$ of the center of the image (created by the point source) is given by the following relation [54]:

$$
\begin{gathered}
L\left(\frac{2 \pi \varepsilon a r}{c h D}\right)=1-J_{0}^{2}\left(\frac{2 \pi \varepsilon a r}{c h D}\right)-J_{1}^{2}\left(\frac{2 \pi \varepsilon a r}{c h D}\right), \\
D \equiv R_{d}-R_{p} .
\end{gathered}
$$

In these expressions $J_{0}$ and $J_{1}$ are Bessel functions of order 0 and 1 (respectively), $c$ is the speed of light, $h$ is Planck's constant, $D$ is the distance from the pinhole to the image plane, $R_{d}$ is the distance from the source to the detector (image plane), and $R_{p}$ is the distance from the source to the pinhole. Equation (7) makes a thin-aperture assumption, which is valid when the characteristic diffraction angles are small.

Each pinhole plate of the TEP system has, of course, not 1 but 1444 pinholes. The diode detector samples a different part of each of the 1444 identical images produced by the source. Assuming that the source, pinhole plate, and detector are perfectly aligned, and that the source is effectively a point source, the detector would sample the image out to a distance of approximately

$$
r_{\mathrm{eff}} \sim \frac{(n-1) d R_{d}}{\pi^{1 / 2} R_{p}}
$$

from the center of the image. Equation (9) assumes a square array with $n \times n$ pinholes. The distance $r_{\text {eff }}$ is an effective radius of the pinhole array when the array is projected from the pinhole-array location $R_{p}$ to the location $R_{d}$ of the detector (image) plane.

The $\mathrm{x}$-ray source can be considered as a point source whenever the diffracted image is much larger than the image would be in the absence of diffraction. It is straightforward to show that under this condition, and when $\left(x_{\text {source }} D / R_{p}\right) \ll 2 r_{\text {eff }}$ where $x_{\text {source }}$ is a characteristic spatial dimension of the source, the fraction of the $\mathrm{x}$-ray power in the diffracted image that is sampled by the diode detector is given by Eqs. (7)-(9):

$$
f_{\text {diff }}(\varepsilon)=L\left(\frac{2 \pi \varepsilon a r_{\mathrm{eff}}}{c h D}\right) .
$$

Equation (10) is reasonably accurate even when the source cannot be considered as a point source, as long as $\left(x_{\text {source }} D / R_{p}\right) \ll 2 r_{\text {eff }}$.

Consequently, when Eq. (10) is applicable and most of the $\mathrm{x}$ rays transmitted by the array-mask combination are transmitted through the pinholes, the pinhole-array attenuation ratio in the presence of diffraction $p(\varepsilon)$ is approximately:

$$
p(\varepsilon)=f_{\text {trans }}(\varepsilon) f_{\text {diff }}(\varepsilon) .
$$

For the TEP system described in this article,

$$
\begin{aligned}
n & =38, \\
R_{p} & =19 \mathrm{~m}, \\
R_{d} & =24 \mathrm{~m} .
\end{aligned}
$$

Assuming Eqs. (2), (3), (7)-(10), and (12)-(14), $f_{\text {diff }}(\varepsilon)$ is as plotted in Fig. 5. Assuming Eq. (11) and the functions $f_{\text {trans }}(\varepsilon)$ and $f_{\text {diff }}(\varepsilon)$ plotted in Fig. 5, we obtain the function $p(\varepsilon)$ that is also plotted. As indicated by this figure, for photon energies between 100 and $10000 \mathrm{eV}$, an array-mask combination defined by Eqs. (2)-(6) and (12)-(14) attenuates the x-ray flux by a factor of $\sim 1800$.

According to Eqs. (7)-(11), as $n \rightarrow \infty$, then $f_{\text {diff }}(\varepsilon) \rightarrow 1$ and $p(\varepsilon) \rightarrow f_{\text {trans }}(\varepsilon)$. Hence for pinhole arrays with infinite extent, the x-ray flux at the detector is unaffected by diffraction.

\section{B. Sensitivity of an array-diode combination as a function of $\varepsilon$}

We define $d \Phi(\varepsilon)$ to be the differential x-ray flux (power per unit area) in the energy interval between $\varepsilon$ and $\varepsilon+d \varepsilon$ that would be present at the diode in the absence of the pinhole array. Given the experimental arrangement shown in Fig. 1, the differential flux in the presence of the array $d \phi(\varepsilon)$ is then

$$
d \phi(\varepsilon)=p(\varepsilon) d \Phi(\varepsilon)
$$

where $p(\varepsilon)$ is defined by Eq. (11).

The region inside the cathode-electrode ring illustrated in Fig. 3 is covered with an $8-11 \mathrm{~nm}$ thick passivation layer of $\mathrm{SiO}_{2}$ [51]. The active region of silicon beneath the passivation layer is $\sim 14 \mu \mathrm{m}$ thick, and there is no significant dead layer [51]. We make the simplifying assumption that, for x-rays with energies of interest, an electron-hole pair is created in the active region for every $3.66 \mathrm{eV}$ of 
energy deposited in the region; i.e., that the diode generates $0.273 \mathrm{~A}$ per $\mathrm{W}$ of power absorbed in this region [31].

Hence, the differential output current $d I(\varepsilon)$ of an apertured silicon-diode detector due to the x-ray flux $d \phi(\varepsilon)$ can be expressed as follows [32]:

$$
d I(\varepsilon)=\gamma A_{d} f_{\mathrm{Si}}(\varepsilon) d \phi(\varepsilon)=\gamma A_{d} f_{\mathrm{Si}}(\varepsilon) p(\varepsilon) d \Phi(\varepsilon)
$$

where

$$
\begin{gathered}
\gamma \equiv 0.273 \mathrm{~A} / \mathrm{W} \\
\left.f_{\mathrm{Si}}(\varepsilon)=\left\{\exp \left[-\mu_{\mathrm{SiO}_{2}}(\varepsilon) x_{\mathrm{SiO}_{2}}\right]\right\} 1-\exp \left[-\mu_{\mathrm{Si}}(\varepsilon) x_{\mathrm{Si}}\right]\right\}
\end{gathered}
$$

In the above equations $\gamma$ is the intrinsic sensitivity of the silicon, $A_{d}$ is the area of the diode's aperture, $f_{\mathrm{Si}}(\varepsilon)$ is the fraction of the x-ray flux incident upon the diode that is absorbed by the diode's active silicon region, $\mu_{\mathrm{SiO}_{2}}(\varepsilon)$ is the attenuation coefficient of the diode's $\mathrm{SiO}_{2}$ passivation layer (in units of inverse length), $x_{\mathrm{SiO}_{2}}$ is the passivationlayer thickness, $\mu_{\mathrm{Si}}(\varepsilon)$ is the attenuation coefficient of the active region of the diode (in units of inverse length), and $x_{\mathrm{Si}}$ the thickness of the active region. Equation (18) neglects backscattering of $\mathrm{x}$ rays from the silicon, and energy lost from the silicon due to electron loss and fluorescence.

From Eq. (16) we obtain an expression for the theoretical sensitivity $S(\varepsilon)$ (in units of $\mathrm{A} / \mathrm{W}$ ) of an array-diode system:

$$
S(\varepsilon) \equiv \frac{1}{A_{d}} \frac{d I(\varepsilon)}{d \Phi(\varepsilon)}=\gamma f_{\mathrm{Si}}(\varepsilon) p(\varepsilon)
$$

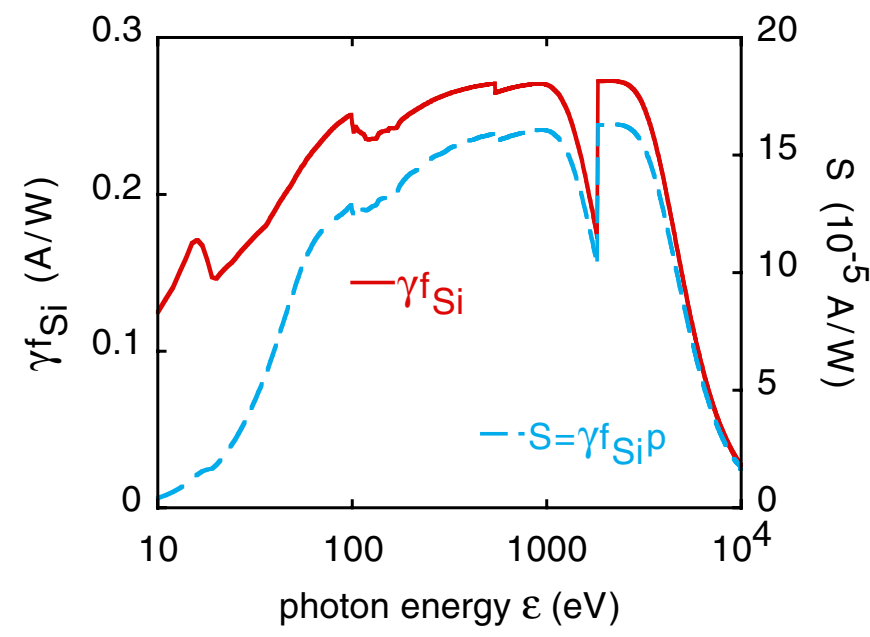

FIG. 6. (Color) The sensitivity $\gamma f_{\mathrm{Si}}(\varepsilon)$ of an HS- 1 silicon diode, and the sensitivity $S(\varepsilon) \equiv \gamma f_{\mathrm{Si}}(\varepsilon) p(\varepsilon)$ of an array-diode combination. The quantity $\gamma$ is the intrinsic sensitivity of silicon (which is $0.273 \mathrm{~A} / \mathrm{W}$ ), $f_{\mathrm{Si}}(\varepsilon)$ is the fraction of $\mathrm{x}$ rays incident upon a diode that is absorbed by the diode's $14-\mu$ m-thick activesilicon region, and $p(\varepsilon)$ is the attenuation ratio of an array-mask combination. The sensitivities are plotted as a function of the X-ray energy $\varepsilon$.
Equation (19) gives the sensitivity as a function of the $\mathrm{x}$-ray energy $\varepsilon$, and is directly applicable when the $\mathrm{x}$ rays are monoenergetic. Figure 6 plots both $\gamma f_{\mathrm{Si}}(\varepsilon)$ and $S(\varepsilon)$ as a function of $\varepsilon$ assuming Eqs. (1)-(19), and that

$$
\begin{gathered}
x_{\mathrm{SiO}_{2}}=9.5 \mathrm{~nm}, \\
x_{\mathrm{Si}}=14 \mu \mathrm{m} .
\end{gathered}
$$

Figure 6 assumes the x-ray-attenuation coefficients $\mu_{\mathrm{SiO}_{2}}(\varepsilon)$ and $\mu_{\mathrm{Si}}(\varepsilon)$ given by Refs. [52,53].

\section{Sensitivity of an array-diode combination as a function of $\boldsymbol{T}_{b}$}

The total diode current $I$ is obtained by integrating Eq. (16):

$$
I=\int_{0}^{\infty} A_{d} S(\varepsilon) \frac{d \Phi(\varepsilon)}{d \varepsilon} d \varepsilon .
$$

Assuming (i) that the x-ray source is a Lambertian emitter, (ii) the x-ray spectrum can be approximated as that of a blackbody, and (iii) the experimental arrangement is as indicated by Fig. 1, we have that [55]

$$
\frac{d \Phi(\varepsilon)}{d \varepsilon}=\left(\frac{A_{s} \sin \vartheta}{\pi^{2} R_{d}^{2}}\right) \frac{2 \pi \varepsilon^{3}}{h^{3} c^{2}\left[\exp \left(\varepsilon / k T_{b}\right)-1\right]} .
$$

In this expression $A_{s}$ is the surface area of the apertured xray source, $\vartheta$ is the diagnostic viewing angle as defined by Fig. $1, k$ is the Boltzmann constant, and $T_{b}$ is the blackbody temperature.

The area $A_{s}$ is, of course, not necessarily the same as the area of the source's aperture. For example, for the measurements described herein, the pinch is apertured so that only $50 \%$ of the pinch length is viewed by the TEP system. If $50 \%$ of the pinch (at stagnation) can be modeled as a 2-mm-diameter 5-mm-length cylinder, then $A_{s}=3.14 \times$ $10^{-5} \mathrm{~m}^{2}$, which is not necessarily the area of the pinch's aperture.

Combining Eqs. (22) and (23), we obtain the diode current as a function of the blackbody temperature $I\left(T_{b}\right)$ for the array-diode configuration presented in Fig. 1:

$$
I\left(T_{b}\right)=\left(\frac{2 A_{d} A_{s} \sin \vartheta}{\pi h^{3} c^{2} R_{d}^{2}}\right) \int_{0}^{\infty} \frac{S(\varepsilon) \varepsilon^{3}}{\exp \left(\varepsilon / k T_{b}\right)-1} d \varepsilon .
$$

Assuming Eq. (24), the sensitivity $\Sigma\left(T_{b}\right)$ [in units of $\left.\mathrm{A} /\left(\mathrm{W} \mathrm{m}^{2}\right)\right]$ of an array-diode system can be expressed as

$$
\begin{aligned}
\Sigma\left(T_{b}\right) & \equiv \frac{I\left(T_{b}\right)}{A_{d} P_{s}\left(T_{b}\right)} \\
& =\left(\frac{2 \sin \vartheta}{\pi h^{3} c^{2} \sigma R_{d}^{2} T_{b}^{4}}\right) \int_{0}^{\infty} \frac{S(\varepsilon) \varepsilon^{3}}{\exp \left(\varepsilon / k T_{b}\right)-1} d \varepsilon,
\end{aligned}
$$

where

$$
P_{s} \equiv A_{s} \sigma T_{b}^{4}
$$


is the total power radiated by the apertured source. Figure 7 plots $\Sigma\left(T_{b}\right)$ as a function of $T_{b}$. This plot assumes Eqs. (1)(26) and that

$$
\vartheta=78 \text { degrees. }
$$

As indicated by the figure, $\Sigma\left(T_{b}\right)$ is relatively independent of $T_{b}$ for $50 \leq T_{b} \leq 350 \mathrm{eV}$.

\section{Spectral sensitivity of a nickel bolometer}

The design and sensitivity of a thin-film nickel bolometer are described in Refs. [37,38]. In this section, we review only the relative spectral dependence of a bolometer's sensitivity $[37,38]$.

The relative sensitivity is determined primarily by the fraction $f_{\mathrm{Ni}}(\varepsilon)$ of the incident $\mathrm{x}$-ray flux that is absorbed by the 1- $\mu \mathrm{m}$-thick nickel film that constitutes the bolometer's detecting element $[37,38]$ :

$$
f_{\mathrm{Ni}}(\varepsilon)=1-\exp \left[-\mu_{\mathrm{Ni}}(\varepsilon) x_{\mathrm{Ni}}\right]
$$

Equation (28) neglects backscattering of $\mathrm{x}$ rays from the nickel, and energy lost from the nickel due to electron loss and fluorescence. Figure 8 plots $f_{\mathrm{Ni}}(\varepsilon)$ as a function of $\varepsilon$, assuming $\mu_{\mathrm{Ni}}(\varepsilon)$ is as given by Refs. [52,53], and

$$
x_{\mathrm{Ni}}=1.0 \mu \mathrm{m} .
$$

Equation (28) and Fig. 8 are directly applicable when the $\mathrm{x}$-rays are monoenergetic. When the x-ray spectrum can be

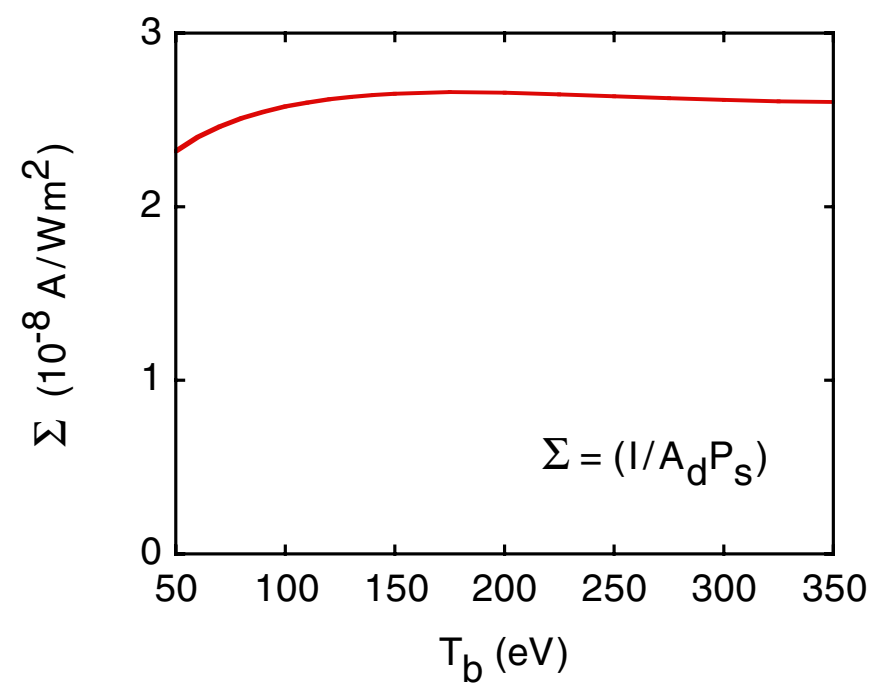

FIG. 7. (Color) The sensitivity $\Sigma\left(T_{b}\right) \equiv I\left(T_{b}\right) / A_{d} P_{s}\left(T_{b}\right)$ of an array-diode combination, assuming the $\mathrm{x}$-ray source emits as a blackbody. The quantity $I$ is the output current of a silicon diode, $A_{d}$ is the area of the diode's aperture, and $P_{s}$ is the total x-ray power radiated by the apertured source. The sensitivity is plotted as a function of the blackbody temperature $T_{b}$.

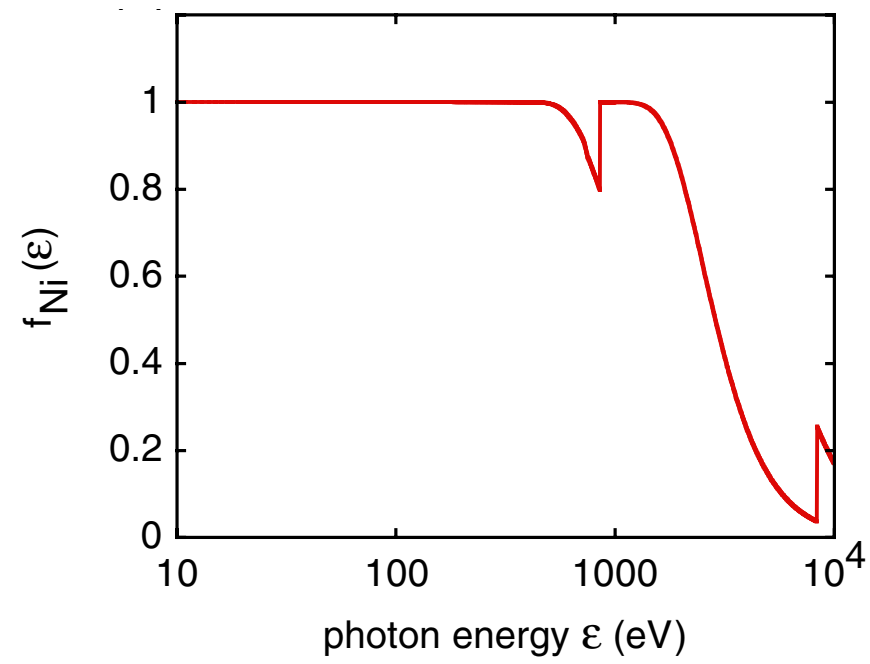

FIG. 8. (Color) The fraction $f_{\mathrm{Ni}}(\varepsilon)$ of $\mathrm{x}$ rays with energy $\varepsilon$ incident upon a $1-\mu \mathrm{m}$-thick nickel film that is absorbed by the film, as a function of $\varepsilon$.

approximated as that of a blackbody at temperature $T_{b}$, the fraction of the x-ray flux absorbed by the nickel film is instead given by

$$
f_{\mathrm{Ni}}\left(T_{b}\right)=\frac{2 \pi}{h^{3} c^{2} \sigma T_{b}^{4}} \int_{0}^{\infty} \frac{\left\{1-\exp \left[-\mu_{\mathrm{Ni}}(\varepsilon) x_{\mathrm{Ni}}\right]\right\} \varepsilon^{3} d \varepsilon}{\exp \left(\varepsilon / k T_{b}\right)-1} .
$$

Figure 9 plots $f_{\mathrm{Ni}}\left(T_{b}\right)$ as a function of $T_{b}$, assuming Eq. (29) and the attenuation coefficient $\mu_{\mathrm{Ni}}(\varepsilon)$ given by Refs. [52,53]. As indicated by the figure, the bolometer sensitivity is relatively independent of $T_{b}$ for $50 \leq T_{b} \leq$ $350 \mathrm{eV}$.

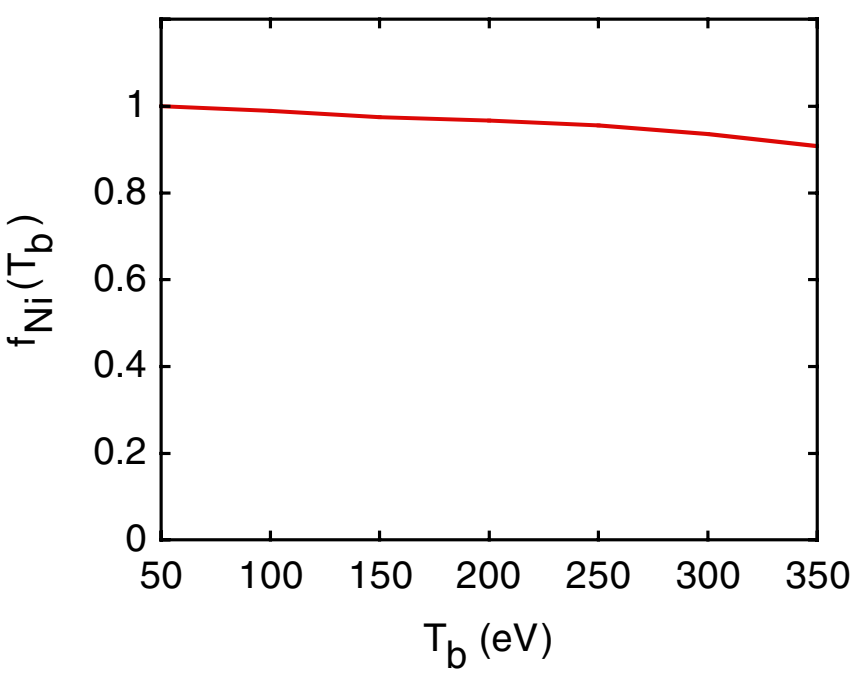

FIG. 9. (Color) The fraction $f_{\mathrm{Ni}}\left(T_{b}\right)$ of the x-ray flux incident upon a $1-\mu \mathrm{m}$-thick nickel film that is absorbed by the film, assuming the $\mathrm{x}$ rays have a blackbody spectrum. The fraction is plotted as a function of the blackbody temperature $T_{b}$. 


\section{E. Maximum energy and power that can be diagnosed by a TEP system}

\section{Maximum energy}

The maximum value of the total radiated $x$-ray energy that can be diagnosed by a TEP system is determined by the peak value of the temperature reached in the tantalum pinhole plates and nickel bolometers.

Neglecting thermal diffusion and radiative cooling, the peak temperature rise $\Delta T$ in a tantalum plate exposed to a normally incident pulsed soft x-ray fluence (energy per unit area) is highest at the surface of the tantalum. Assuming that the X-ray spectrum is that of a blackbody at temperature $T_{b}$, it is straightforward to show that $\Delta T$ is given by

$$
\begin{gathered}
\Delta T=\frac{\tau}{\rho_{\mathrm{Ta}} c_{\mathrm{Ta}}} \int_{0}^{\infty} \mu_{\mathrm{Ta}}(\varepsilon) \frac{d \Phi_{\mathrm{Ta}}(\varepsilon)}{d \varepsilon} d \varepsilon, \\
\frac{d \Phi_{\mathrm{Ta}}(\varepsilon)}{d \varepsilon} \equiv\left(\frac{A_{s} \sin \vartheta}{\pi^{2} R_{\mathrm{Ta}}^{2}}\right) \frac{2 \pi \varepsilon^{3}}{h^{3} c^{2}\left[\exp \left(\varepsilon / k T_{b}\right)-1\right]} .
\end{gathered}
$$

In these expressions $\tau$ is the temporal width of the radiation pulse, $\rho_{\mathrm{Ta}}$ is the tantalum mass density, $c_{\mathrm{Ta}}$ is the specific heat of tantalum at constant pressure, and $d \Phi_{\mathrm{Ta}}(\varepsilon)$ is the differential x-ray flux (power per unit area) at the surface of the tantalum. Equation (31) assumes $\rho_{\mathrm{Ta}}$ and $c_{\mathrm{Ta}}$ are approximately constant for tantalum temperatures of interest. Expressions analogous to Eqs. (31) and (32) are obtained for the nickel film of the bolometers.

Equations (31) and (32) assume that over the time period $\tau$, the blackbody temperature $T_{b}$ is constant. Under this condition, the total energy radiated by the apertured x-ray source $E_{s}$ is

$$
E_{s}=\tau P_{s}=\tau A_{s} \sigma T_{b}^{4} .
$$

Figure 10 plots $\Delta T / E_{s}$ as a function of $T_{b}$ for both tantalum and nickel, assuming

$$
\begin{gathered}
R_{\mathrm{Ta}}=R_{p}=19 \mathrm{~m}, \\
R_{\mathrm{Ni}}=19 \mathrm{~m} .
\end{gathered}
$$

The melting points of tantalum and nickel are $3017^{\circ} \mathrm{C}$ and $1455^{\circ} \mathrm{C}$, respectively. If we choose to limit the theoretical temperature rise $\Delta T$ in the tantalum to $2900^{\circ} \mathrm{C}$, and assume that the $\mathrm{x}$-ray source can be approximated as a 200$\mathrm{eV}$ blackbody, we estimate that the maximum radiated energy that can be diagnosed by the array-diode system described in this article is $1.74 \mathrm{MJ}$. If we choose to limit the temperature rise $\Delta T$ in the nickel to $1400^{\circ} \mathrm{C}$, we find that the maximum energy that can be diagnosed by the bolometer is $2.39 \mathrm{MJ}$. (Hence if the TEP views $50 \%$ of the length of a $z$ pinch, the corresponding energies radiated by the entire pinch would be 3.47 and $4.78 \mathrm{MJ}$, respectively.)

As suggested above, the actual temperature rise is less than that calculated by Eq. (31) due to thermal conduction and radiative cooling. We also do not consider here the

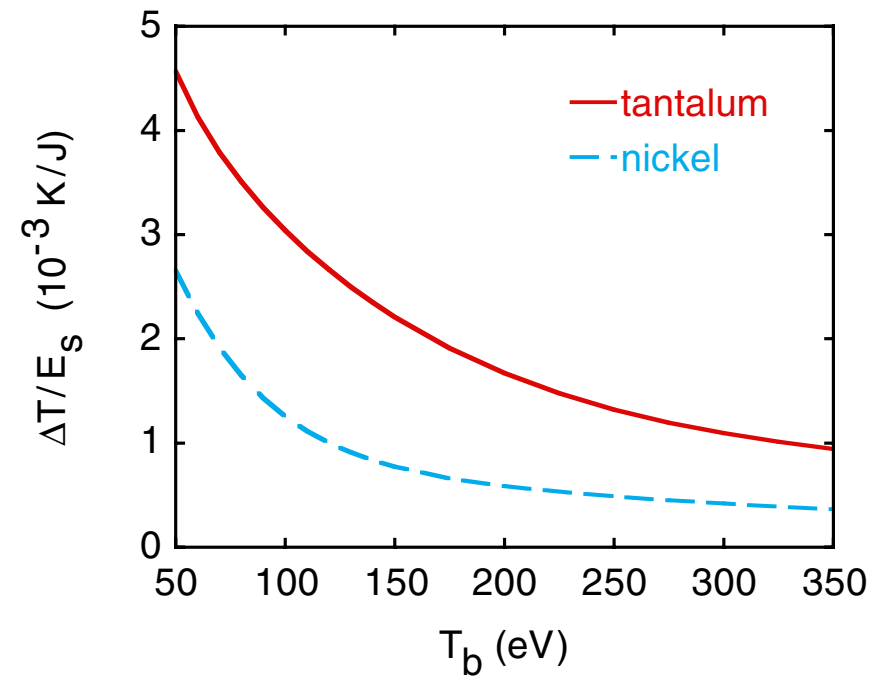

FIG. 10. (Color) The temperature rise at the front surface of the tantalum pinhole plate, and also that of the nickel bolometer, per unit energy radiated by a blackbody x-ray source. The quantity $\Delta T / E_{s}$ is plotted as a function of the source's blackbody temperature $T_{b}$.

additional energy that would be required to complete the phase transition from solid to liquid.

Equation (31) suggests that if a pinhole plate were fabricated from a material with a lower atomic number (and hence, a smaller x-ray-attenuation coefficient) than that of tantalum, the plate would experience a lower temperature rise at its surface. However, tantalum is an attractive pinhole-plate material precisely because of its high atomic number. It addition, tantalum has a high mass density and a high melting point, and thin sheets can be laser machined to produce small pinholes. Similarly, Eq. (31) suggests that the temperature rise at a bolometer's surface could be reduced by choosing a material other than nickel. However, nickel is attractive because of its high temperature coefficient of resistivity, and reasonably high mass density, atomic number, and melting point. Nickel can also be used to make the $\sim 1-\mu \mathrm{m}$-thick films necessary for a bolometer. Nevertheless, tantalum and nickel are discussed here only because they provide reasonable overall performance; for a given application, it may be possible to identify other materials with superior characteristics.

\section{Maximum power}

According to Idzorek and Bartlett [32], when the bias voltage applied to an HS-1 silicon diode is $50 \mathrm{~V}$, the diode response is approximately linear for output currents as high as $0.2 \mathrm{~A}$. According to Fig. 7 , the ratio $I_{b}\left(T_{b}\right) / P_{s}$ $\sim 10^{-15} \mathrm{~A} / \mathrm{W}$ when $A_{d}=4 \times 10^{-8} \mathrm{~m}^{2}$ and $50 \leq T_{b} \leq$ $350 \mathrm{eV}$. Hence over this temperature range, we estimate that the maximum value of $P_{s}$ that can be diagnosed by the diodes of the TEP system (when the diodes are operated in the linear regime) is $200 \mathrm{TW}$. When the TEP system views 
$50 \%$ of the length of a $z$ pinch, the corresponding power radiated by the entire pinch would be 400 TW.

The 200-TW limit assumes that the pinhole array consists of $10-\mu \mathrm{m}$-diameter pinholes on a $361-\mu \mathrm{m}$ grid. Higher x-ray powers could be diagnosed with smallerdiameter pinholes; however, smaller pinholes are more difficult to machine, and have larger diameter variations and increased diffractive effects. Alternatively, the pinholes could be spaced farther apart; however, this would reduce the fraction of each image that is observed by the array's associated diode. Nevertheless, we note that the 200-TW limit discussed above could be increased by decreasing the $\mathrm{x}$-ray transmission of the pinhole array.

\section{ENERGY AND POWER MEASUREMENTS OBTAINED WITH THE TEP}

In this section we present typical measurements obtained with the prototype TEP system described in Secs. I, II, and III. The measurements are summarized in Fig. 11, Table II, and Table III.

The measurements were obtained on $Z$-accelerator shot 1075. An array of five filtered XRDs were also fielded on this shot $[12,13,15,18]$. The XRD array and the TEP's two silicon diodes were separated by $0.4^{\circ}$, and viewed nominally the same axial section of the pinch. The XRD array and bolometers were separated by $0.6^{\circ}$, and also viewed nominally the same region of the pinch.

Figure 11 plots three normalized $\mathrm{x}$-ray-power waveforms. Two of the waveforms were produced by the silicon diodes; the third is a spectrally equalized linear combination of the five XRD signals [18]. The linear combination is

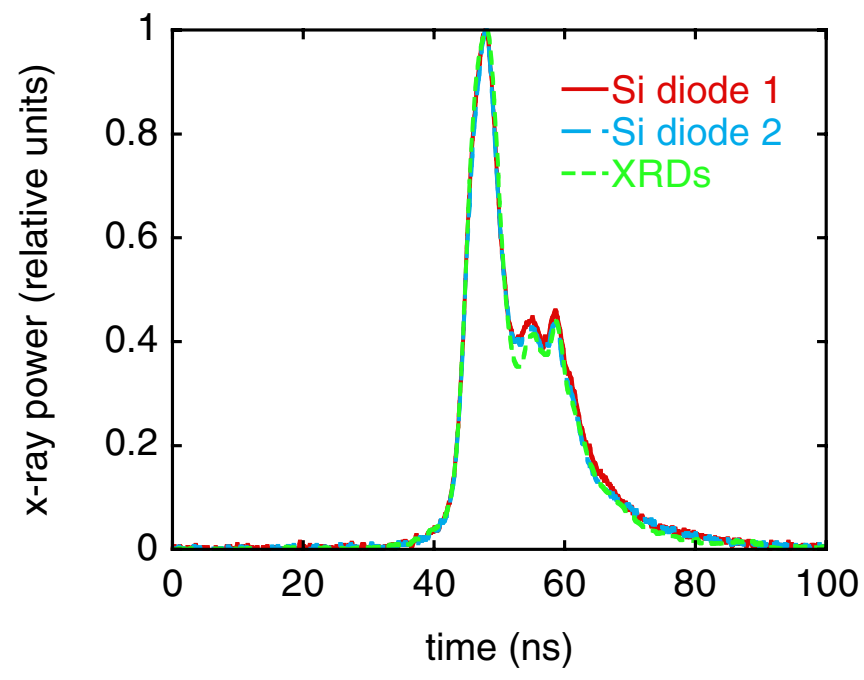

FIG. 11. (Color) X-ray-power waveforms recorded on $Z$-accelerator shot 1075 by the two silicon diodes of the TEP system. Also shown is a spectrally equalized linear combination [18] of five filtered XRD detectors $[12,13,15,18]$ that were fielded on the shot. All three waveforms have been normalized to facilitate comparisons of the pulse shapes.
TABLE II. Summary of radiated x-ray-energy measurements performed on $Z$-accelerator-shot 1075 . Each energy is that which is radiated until $27.5 \mathrm{~ns}$ after peak $\mathrm{x}$-ray power. The measurements given here are for $50 \%$ of the length of the $z$ pinch; the energy radiated by the entire pinch is twice that given here.

\begin{tabular}{lc}
\hline \hline \multicolumn{1}{c}{ Detector } & $\begin{array}{c}\text { Total radiated } \\
\text { X-ray energy }\end{array}$ \\
\hline Bolometer 1 & $0.788 \mathrm{MJ}$ \\
Bolometer 2 & $0.896 \mathrm{MJ}$ \\
Bolometer average & $\mathbf{0 . 8 4 2} \mathbf{M J}$ \\
Silicon-diode 1 & $0.811 \mathrm{MJ}$ \\
$\quad$ [processed assuming Eq. (25)] & $0.915 \mathrm{MJ}$ \\
Silicon-diode 2 & \\
$\quad$ [processed assuming Eq. (25)] & $\mathbf{0 . 8 6 3 ~ M J}$ \\
\hline \hline
\end{tabular}

approximately proportional to the x-ray power, as discussed by Fehl and colleagues in Ref. [18]. The normalized standard deviation of the pointwise difference between the two silicon-diode waveforms is $0.7 \%$. The pointwise difference between each of the silicon-diode waveforms and the XRD waveform is on the order of $1 \%$. It is interesting to note that the ripples in the tails of the silicon-diode signals are similar to the ripples in the linear combination of the XRD signals.

The x-ray-energy measurements obtained with the TEP system are summarized in Table II. The two bolometer measurements differ by $14 \%$. This discrepancy is due to uncertainties in (i) the mass densities, specific heats, and temperature coefficients of resistivity of the two nickel

TABLE III. Summary of radiated x-ray-power measurements on $Z$-accelerator-shot 1075 . The measurements given here are for $50 \%$ of the length of the $z$ pinch; the peak $\mathrm{x}$-ray power radiated by the entire pinch is twice that given here.

\begin{tabular}{|c|c|}
\hline Detector & $\begin{array}{c}\text { Peak radiated } \\
\text { X-ray power }\end{array}$ \\
\hline $\begin{array}{l}\text { Silicon-diode } 1 \\
\text { (normalized to the average bolometer energy) }\end{array}$ & $72 \mathrm{TW}$ \\
\hline $\begin{array}{l}\text { Silicon-diode } 2 \\
\text { (normalized to the average bolometer energy) }\end{array}$ & $74 \mathrm{TW}$ \\
\hline $\begin{array}{l}\text { Silicon-diode average } \\
\text { (average of the above two powers) }\end{array}$ & 73 TW \\
\hline $\begin{array}{l}\text { Silicon-diode } 1 \\
\quad \text { [processed assuming Eq. (25)] }\end{array}$ & 69 TW \\
\hline $\begin{array}{l}\text { Silicon-diode } 2 \\
\quad \text { [processed assuming Eq. (25)] }\end{array}$ & $81 \mathrm{TW}$ \\
\hline $\begin{array}{l}\text { Silicon-diode average } \\
\quad \text { (average of the above two powers) }\end{array}$ & 75 TW \\
\hline $\begin{array}{l}\text { XRD array } \\
\text { (spectrally equalized linear combination } \\
\text { of five XRDs [18], normalized to the } \\
\text { average bolometer energy) }\end{array}$ & 74 TW \\
\hline
\end{tabular}


films; (ii) the widths and thicknesses of the films; and (iii) the current and voltage measurements used to infer the resistance change of the films $[37,38]$. We note that the sensitivity of a bolometer is inversely proportional to the square of both its film width and thickness [37,38]. Also contributing to the discrepancy is the fact that, since the two bolometers were slightly displaced from each other, they viewed slightly different regions of the pinch. (Work is in progress to reduce the discrepancy to below 14\%.)

The average of the two bolometer measurements is given in the 3rd row of Table II, which indicates that the energy radiated by the apertured pinch (i.e., by $50 \%$ of the pinch length) was $0.842 \mathrm{MJ}$.

We also obtain an estimate of the radiated energy from the silicon-diode signals. Using Eq. (25), the measured values of the average pinhole diameters given in Table I, and measured values of $A_{d}$ for each of the two diodes, we obtain the x-ray energies listed in the 4th and 5th rows of Table II. The two diode measurements differ by $13 \%$. This discrepancy is due to uncertainties in (i) the areas of the tantalum apertures used to aperture the diodes; (ii) how well each diode aperture was aligned with its associated diode's electrode ring, and (iii) the diameters of the pinholes that contributed the most to the diode signals. (We estimate that on $Z$-shot 1075 , the blackbody temperature of the pinch near peak $\mathrm{x}$-ray power was $200 \mathrm{eV}$. At this temperature, the x-ray spectrum peaks at $560 \mathrm{eV}$. At this energy, diffractive blurring of the image is such that for each array-diode combination, $\sim 20$ pinholes are responsible for half the diode signal. Because we do not presently have a method of determining the precise relative position of a pinhole array with respect to its associated diode, we do not know which 20 of the 1444 pinholes contributed to each diode's signal on shot 1075 . Hence we are forced to use the average measurements listed in Table I.) Also contributing to the discrepancy is the fact that the two diodes viewed slightly different regions of the pinch.

The average of the two diode measurements is given in the 6th row of Table II, which indicates that the energy radiated by the apertured pinch (i.e., by $50 \%$ of the pinch length) was $0.863 \mathrm{MJ}$.

As indicated by the 3rd and 6th rows of Table II, the two methods described above give radiated energies that are in reasonable agreement. However, agreement at the level indicated by Table II must be considered fortuitous, for the following reasons. As discussed above, for each arraydiode combination, $\sim 20$ pinholes were responsible for half the diode signal. Assuming the pinhole measurements presented in Table I, we estimate that the $1 \sigma$ uncertainty in the average area of any 20 pinholes is $5 \%$; the $2 \sigma$ uncertainty is $10 \%$. Consequently, since we take the average of two diode signals, we cannot expect the energy measurements given in the 3rd and 6th rows of Table II to agree to within better than $\left(10 \% / 2^{1 / 2}\right)=7 \%$.

The average bolometer energy given in the 3rd row of Table II is used to perform an in situ calibration of the two array-diode systems, as follows. As indicated by Table II, the bolometers find that the energy radiated by the apertured pinch until $27.5 \mathrm{~ns}$ after peak x-ray power was $0.842 \mathrm{MJ}$. We assume that the silicon-diode signals plotted in Fig. 11 are proportional to the x-ray power $P_{s}$, as suggested by Fig. 7. We integrate the diode signals, and set each integrated signal at time $t=75.5 \mathrm{~ns}$ (which is $27.5 \mathrm{~ns}$ after peak power) equal to $0.842 \mathrm{MJ}$ to obtain the proportionality constant for each of the two array-diode combinations. This method provides the peak $\mathrm{x}$-ray powers listed in rows $1-3$ of Table III.

We also estimate the $\mathrm{x}$-ray power from the silicon diodes without using the bolometer energy. We use Eq. (25), the measured pinhole diameters given in Table I, and measured values of $A_{d}$ for each silicon diode to obtain the x-ray powers listed in rows $4-6$ of Table III. The powers listed in rows 4 and 5 differ by $17 \%$, which we attribute to the same factors listed above for the difference between rows 4 and 5 of Table II.

As indicated by Table III, the average power obtained by normalizing the diodes to the bolometer energy (the power given in the 3rd row of Table III) is in good agreement with the average power obtained from the theoretical arraydiode model given by Eq. (25) (the power given in the 6 th row of Table III). However, for the reasons given above, agreement between these two powers at the level indicated by Table III must be considered fortuitous, since we cannot expect these powers to agree to within better than $7 \%$.

Given the inherent uncertainties in the diode measurements discussed above, we expect that the x-ray power obtained by normalizing the silicon-diode signals to the average bolometer energy is more accurate than the power obtained using only Eq. (25).

In addition to the peak x-ray-power measurements discussed above, we also obtain a power measurement from the normalized linear combination of the XRD signals [18]. This power, which is given in the 7 th row of Table III, is consistent with the powers given in the 3rd and 6 th rows of the table.

\section{RECOMMENDATIONS FOR FUTURE WORK}

The TEP system described in Secs. I, II, and III has a sensitivity that is relatively flat for blackbodies with temperatures between 50 and $350 \mathrm{eV}$. For temperatures below $50 \mathrm{eV}$ (i.e., when the characteristic x-ray energy is below $140 \mathrm{eV}$ ), pinhole diffraction reduces significantly the sensitivity of the array-diode combination, as indicated by Figs. 5-7. For temperatures above $350 \mathrm{eV}$ (i.e., when the characteristic x-ray energy is above $990 \mathrm{eV}$ ), the x-rayabsorption efficiency of the bolometer decreases significantly, as indicated by Figs. 8 and 9 .

The temperature range of the TEP system could be extended below $50 \mathrm{eV}$ by increasing the spatial extent of the pinhole array. (Increasing the extent would also make 
the system less sensitive to slight misalignments.) The temperature range could be extended above $350 \mathrm{eV}$ by designing a nickel bolometer with a film thicker than $1 \mu \mathrm{m}$, or using a film with a higher atomic number or mass density. Alternatively, the bolometer could be replaced by a calorimeter with an absorber that is less transparent to $\mathrm{x}$ rays than $1-\mu \mathrm{m}$-thick nickel, such as the calorimeter described by Fehl and colleagues in Ref. [48].

The limits discussed in Sec. IIIE on the energy and power that can be diagnosed by a TEP system could, of course, be increased by moving the system's pinhole arrays, diodes, and bolometers further from the source. However, this might require the development of an improved alignment process. The system described herein is aligned manually, which is somewhat tedious, since the arrays and diodes are located 19 and $24 \mathrm{~m}$ from the source, respectively.

Since the bolometers are used to provide the total radiated x-ray energy and, in addition, in situ calibrations of the array-diode combinations, systematic uncertainties in the TEP measurements could be reduced by improving the accuracy of the bolometer measurements. Random uncertainties could, of course, be reduced by fielding more than two array-diode combinations and two bolometers.

\section{ACKNOWLEDGMENTS}

The authors would very much like to thank D. Jobe, M. Johnson, R. Korde, S. Lazier, M. K. Matzen, D. Muron, P. Reynolds, J. J. Seamen, and R. Smelser for invaluable contributions, and T. Cutler, B. Ives, P. Ives, W. Johnson, R. Jorgenson, and M. Lopez for graciously reviewing this article. We also wish to thank our many other colleagues at Sandia National Laboratories, Ktech Corporation, Team Specialty Products, ATK Mission Research Corporation, Bechtel Corporation, C-Lec Plastics, Cornell University, EG\&G, Imperial College, Gull Group, International Radiation Detectors Incorporated, International Specialty Products, Lawrence Livermore National Laboratory, Los Alamos National Laboratory, Mission Research Corporation, Naval Research Laboratory, Prodyn Technologies, Resonetics Incorporated, Titan-Pulse Sciences Division, Tri-Tech Machine Tool Company, the University of California, the University of Nevada, the University of New Mexico, Voss Scientific, Votaw Precision Technologies, and the Weizmann Institute for their sustained support of this work. Sandia is a multiprogram laboratory operated by Sandia Corporation, a Lockheed Martin Company, for the United States Department of Energy's National Nuclear Security Administration under Contract No. DE-AC04-94AL85000.

[1] M. D. Rosen, Phys. Plasmas 3, 1803 (1996).

[2] M. S. Derzon, G. A. Chandler, R. J. Dukart, D. J. Johnson, R J. Leeper, M. K. Matzen, E. J. McGuire, T. A. Mehlhorn,
A. R. Moats, R. E. Olson, and C. L. Ruiz, Phys. Rev. Lett. 76, 435 (1996).

[3] T.W.L. Sanford, R.E. Olson, R.L. Bowers, G. A. Chandler, M.S. Derzon, D.E. Hebron, R. J. Leeper, R. C. Mock, T. J. Nash, D. L. Peterson, L. E. Ruggles, W. W. Simpson, K. W. Struve, and R. A. Vesey, Phys. Rev. Lett. 83, 5511 (1999).

[4] J. E. Bailey, G. A. Chandler, D. Cohen, M. E. Cuneo, M. E. Foord, R. F. Heeter, D. Jobe, P. W. Lake, J. J. MacFarlane, T. J. Nash, D. S. Nielson, R. Smelser, and J. Torres, Phys. Plasmas 9, 2186 (2002).

[5] J. M. Foster, B. H. Wilde, P. A. Rosen, T. S. Perry, M. Fell, M. J. Edwards, B.F. Lasinski, R.E. Turner, and M.L. Gittings, Phys. Plasmas 9, 2251 (2002).

[6] J. D. Lindl, P. Amendt, R. L. Berger, S. G. Glendinning, S. H. Glenzer, S. W Haan, R. L. Kauffman, O. L. Landen, and L. J. Suter, Phys. Plasmas 11, 339 (2004).

[7] M.E. Cuneo, R. A. Vesey, D. B. Sinars, J. P. Chittenden, E. M. Waisman, R. W. Lemke, S. V. Lebedev, D. E. Bliss, W. A. Stygar, J. L. Porter, D. G. Shroen, M. G. Mazarakis, G. A. Chandler, and T. A. Mehlhorn, Phys. Rev. Lett. 95, 185001 (2005).

[8] H. N. Kornblum, R. L. Kauffman, and J. A. Smith, Rev. Sci. Instrum. 57, 2179 (1986).

[9] M. S. Derzon, M. A. Sweeney, P. Grandon, H. C. Ives, R. P. Kensek, L. P. Mix, and W. A. Stygar, Rev. Sci. Instrum. 59, 1834 (1988).

[10] P. Lee, J. Gernhardt, C. J. Armentrout, and R. T. Snider, Rev. Sci. Instrum. 59, 883 (1988).

[11] R. J. Leeper et al., Rev. Sci. Instrum. 68, 868 (1997).

[12] G. A. Chandler, C. Deeney, M. Cuneo, D. L. Fehl, J. S. McGurn, R. B. Spielman, J. A. Torres, J. L. McKenney, J. Mills, and K. W. Struve, Rev. Sci. Instrum. 70, 561 (1999).

[13] D. L. Fehl, F. Biggs, G. A. Chandler, and W. A. Stygar, Rev. Sci. Instrum. 71, 3072 (2000).

[14] J. L. Bourgade, B. Villette, J. L. Bocher, J. Y. Boutin, S. Chiche, N. Dague, D. Gontier, J. P. Jaduad, B. Savale, R. Wrobel, and R. E. Turner, Rev. Sci. Instrum. 72, 1173 (2001).

[15] T. J. Nash et al., Rev. Sci. Instrum. 72, 1167 (2001).

[16] K. M. Campbell, F. A. Weber, E. L. Dewald, S. H. Glenzer, O. L. Landen, R.E. Turner, and P. Waide, Rev. Sci. Instrum. 75, 3768 (2004).

[17] E. L. Dewald, K. M. Campbell, R. E. Turner, J. P. Holder, O. L. Landen, S. H. Glenzer, R. L. Kauffman, L. J. Suter, M. Landon, M. Rhodes, and D. Lee, Rev. Sci. Instrum. 75, 3759 (2004).

[18] D. L. Fehl, W. A. Stygar, G. A. Chandler, M. E. Cuneo, and C. L. Ruiz, Rev. Sci. Instrum. 76, 103504 (2005).

[19] H. N. Kornblum and W. V. Slivinsky, Rev. Sci. Instrum. 49, 1204 (1978).

[20] J. L. Porter (unpublished).

[21] L. E. Ruggles, J. L. Porter, Jr., and R. Bartlett, Rev. Sci. Instrum. 68, 1063 (1997).

[22] L. E. Ruggles, M. E. Cuneo, J. L. Porter, D. F. Wenger, and W. W. Simpson, Rev. Sci. Instrum. 72, 1218 (2001).

[23] M.C. Hettrick, M.E. Cuneo, J.L. Porter, L. E. Ruggles, W. W. Simpson, M. F. Vargas, and D. F. Wenger, Appl. Opt. 43, 3772 (2004).

[24] K. L. Baker, J. L. Porter, L. E. Ruggles, R. E. Chrien, and G. C. Idzorek, Rev. Sci. Instrum. 70, 1624 (1999). 
[25] R.E. Turner, O.L. Landen, P. Bell, R. Costa, and D. Hargrove, Rev. Sci. Instrum. 70, 656 (1999).

[26] D. R. Kania, L. Pan, H. Kornblum, P. Bell, O. N. Landen, and P. Pianetta, Rev. Sci. Instrum. 61, 2765 (1990).

[27] D. R. Kania, L.S. Pan, P. Bell, O.L. Landen, H. Kornblum, P. Pianetta, and M. D. Perry, J. Appl. Phys. 68, 124 (1990).

[28] R. B. Spielman, Rev. Sci. Instrum. 63, 5056 (1992).

[29] R. B. Spielman, Rev. Sci. Instrum. 66, 867 (1995).

[30] R. B. Spielman, L. E. Ruggles, R. E. Pepping, S. P. Breeze, J. S. McGurn, and K. W. Struve, Rev. Sci. Instrum. 68, 782 (1997).

[31] International Radiation Detectors, Torrance, California 90505-5243, http://www.ird-inc.com/. The HS-1 diode was developed under the DOE SBIR Phase-1 program.

[32] G. C. Idzorek and R. J. Bartlett, Proc. SPIE 3114, 349 (1997).

[33] R. T. Eagleton and L. E. Ruggles, Rev. Sci. Instrum. 72, 1205 (2001).

[34] L.E. Ruggles, J.L. Porter, Jr., P. K. Rambo, W. W. Simpson, M. F. Vargas, G. R. Bennett, and I. C. Smith, Rev. Sci. Instrum. 74, 2206 (2003).

[35] T. W. L. Sanford et al., Rev. Sci. Instrum. 72, 1217 (2001).

[36] W. W. Simpson, J.L. Porter, L.E. Ruggles, and D.F. Wenger, Rev. Sci. Instrum. 72, 1223 (2001).

[37] D. L. Hanson, internal Sandia National Laboratories report (1984).

[38] R. B. Spielman, C. Deeney, D. L. Fehl, D. L. Hanson, N. R. Keltner, J.S. McGurn, and J.L. McKenney, Rev. Sci. Instrum. 70, 651 (1999).

[39] R. B. Spielman, W. A. Stygar, J. F. Seamen, F. Long, H. Ives, R. Garcia, T. Wagoner, K.W. Struve, M. Mostrom, I. Smith, P. Spence, and P. Corcoran, in Proceedings of the 11th IEEE International Pulsed Power Conference, edited by G. Cooperstein and I. Vitkovitsky (IEEE, Piscataway, NJ, 1997), p. 709.

[40] P. A. Corcoran, J. W. Douglas, I. D. Smith, P. W. Spence, W. A. Stygar, K. W. Struve, T. H. Martin, R. B. Spielman, and H.C. Ives, in Proceedings of the 11th IEEE International Pulsed Power Conference (Ref. [39]), p. 466.

[41] R. J. Garcia, H. C. Ives, K. W. Struve, R. B. Spielman, T.H. Martin, M.L. Horry, R. Wavrik, and T.F. Jaramillo, in Proceedings of the 11th IEEE International Pulsed Power Conference (Ref. [39]), p. 1614.

[42] H. C. Ives, D. M. Van De Valde, F. W. Long, J. W. Smith,
R. B. Spielman, W. A. Stygar, R. W. Wavrick, and R. W. Shoup, in Proceedings of the 11th IEEE International Pulsed Power Conference (Ref. [39]), p. 1602.

[43] M. A. Mostrom, T. P. Hughes, R. E. Clark, W. A. Stygar, and R.B. Spielman, in Proceedings of the 11th IEEE International Pulsed Power Conference (Ref. [39]), p. 460.

[44] R. W. Shoup, F. Long, T. H. Martin, R. B. Spielman, W. A. Stygar, M. A. Mostrom, K.W. Struve, H. Ives, P. Corcoran, and I. Smith, in Proceedings of the 11th IEEE International Pulsed Power Conference (Ref. [39]), p. 1608 .

[45] I. D. Smith, P. A. Corcoran, W. A. Stygar, T. H. Martin, R. B. Spielman, and R. W. Shoup, in Proceedings of the 11th IEEE International Pulsed Power Conference (Ref. [39]), p. 168.

[46] K. W. Struve, T. H. Martin, R. B. Spielman, W. A. Stygar, P. A. Corcoran, and J. W. Douglas, in Proceedings of the 11th IEEE International Pulsed Power Conference (Ref. [39]), p. 162.

[47] W. A. Stygar, R. B. Spielman, G. O. Allshouse, C. Deeney, D. R. Humphreys, H. C. Ives, F. W. Long, T. H. Martin, M. K. Matzen, D. H. McDaniel, C. W. Mendel, Jr., L.P. Mix, T. J. Nash, J. W. Poukey, J J. Ramirez, T. W. L. Sanford, J. F. Seamen, D. B. Seidel, J. W. Smith, D. M. Van De Valde, R. W. Wavrik, P. A. Corcoran, J. W. Douglas, I. D. Smith, M. A. Mostrom, K. W. Struve, T. P. Hughes, R. E. Clark, R. W. Shoup, T.C. Wagoner, T. L. Gilliland, and B. Peyton, in Proceedings of the 11th IEEE International Pulsed Power Conference (Ref. [39]), p. 591.

[48] D. L. Fehl, D. J. Muron, R. J. Leeper, G. A. Chandler, C. Deeney, W. A. Stygar, and R. B. Spielman, Rev. Sci. Instrum. 70, 270 (1999).

[49] International Specialty Products, Wayne, New Jersey 07470.

[50] Resonetics Incorporated, Nashua, New Hampshire 03063.

[51] R. Korde (unpublished).

[52] B. L. Henke, E. M. Gullikson, and J. C. Davies, At. Data Nucl. Data Tables 54, 181 (1993).

[53] The data presented in Ref. [52] can be conveniently accessed in electronic form at: http://www-cxro.lbl.gov/ optical_constants/

[54] M. Born and E. Wolf, Principles of Optics (Pergamon, New York, 1980), p. 398.

[55] F. Reif, Fundamentals of Statistical and Thermal Physics (McGraw-Hill, New York, 1965). 